\title{
Adaptive Optimal Sustainability Framework In Urban Water Supply System Under Different Runoff Scenarios
}

Mahdi Moudi ( $\square$ moudi@cuit.edu.cn )

Chengdu University of Information Technology

\section{Research Article}

Keywords: Sustainability of system, Water supply, System performance, Shortage

Posted Date: February 7th, 2022

DOI: https://doi.org/10.21203/rs.3.rs-980003/v2

License: (c) (i) This work is licensed under a Creative Commons Attribution 4.0 International License.

Read Full License 
3 Moudi Mahdi *

4 College of Management, Chengdu University of Information Technology, Chengdu 610103, 5 China.

\section{Adaptive optimal sustainability framework in urban water supply system under different runoff scenarios}

Abstract

Recent droughts have caused a crisis in the water supply procedure, because as available water resources become more limited, the imbalance between the growing water demand and water supply in different sectors leads to unsustainability in the system. Thus, this study proposes a dynamic model to optimize water supply system under different scenarios aimed at improving sustainability of system. In fact, due to the negative impacts of the water crisis, the sustainability of the dynamic water supply system is evaluated and optimized according to the performance indicators of the system. Also, to investigate the proposed model, a real case study of the Sistan basin in Iran over ten years period is conducted. Based on the model, different management insights along with the scenario analysis are considered in order to assess the sustainability of system in more detail. According to the final output, the highest level of sustainability is related to the domestic sector because it has higher reliability and less vulnerability than other sectors.

Keyword: Sustainability of system, Water supply, System performance, Shortage

\section{Introduction}

Due to rapid population growth and climate change, meeting water demand in a regional water supply system has become a major challenge for decision makers (Xiong et al. 2020; Brown et al. 2015). However, the lack of available water resources, along with the lack of proper water supply management, increasingly threatens the sustainability of the urban water supply system, and the

*Corresponding author. E-mail address: moudi@cuit.edu.cn 
environment (Rathnayaka et al. 2016). Indeed, the sustainability of the water supply system depends on improving efficiency of adaptation measures on both supply and demand sides, so that on the demand side, demand management to delay the need for new resources, and on the supply side, rising the efficiency of optimal use of water resources should be considered (Waite 2010). By definition, sustainability of water supply system is formulated as the geometric mean of performance indices: reliability, resilience, and vulnerability; and it reflects the integrated behavior of the system by considering the possible consequences of the imbalance between water demand and water supply (Sandoval-Solis et al. 2011; Srdjevic and Srdjevic 2017). Indeed, the mentioned indices are considered as the main indicators for analyzing the performance of water supply system in the long-run (Gu et al. 2017; Hashimoto et al. 1982), which in sustainable management of largescale water resources planning, in comparison with other cases, they operate as the criteria for the success of sustainable development strategies of system in different hydrological conditions (Srdjevic and Srdjevic 2017). However, the focus of scientific research on the sustainability of the water supply system has recently increased due to runoff uncertainty and the effects of human activities in the basins. For instance, Ryu et al. (2009) developed a multi-criteria decision mechanism (MCDM) by considering subjective scales to analyze the periodic effects of the water resource allocation process on system stainability. Butler et al. (2017) developed an integrated reliability, resilience, and sustainable framework for the sustainable management of water resources, and then, by analyzing the threats related to water system on large scale, and their effects on system performance, socio-economic, and environmental consequences, provided solutions for decision makers of system. Abdi-Dehkordi et al. (2021) proposed a spatial distribution framework based on the system dynamics approach to enhance the sustainability of the water system, so that a set of individual indicators to evaluate the behavior of the water system by considering the quantitative and qualitative aspects of the environment was considered. Jun et al. (2011) proposed 
49 a new framework for the sustainable management of water resources with regard to the four indicators of potential flood damage (PFDC), potential drought damage (PDDC), potential water

51 quality deterioration (PWQDC), and watershed evaluation index (WEIC). Chen et al. (2018)

52 developed a credit-based hierarchical programming model regarding the security of water

53 resources to manage sustainability of regional water system.

54 Although research on sustainability of water supply system has been well highlighted in the

55 literature, recently, the sustainability of the water supply system seems to be addressed as one of

56 the major concerns when it comes to multi-sectoral sustainability. To this end, this paper develops

57 a dynamic optimal framework to improve sustainability of water supply system considering

58 various performance indicators including resilience, reliability, and vulnerability. However, given

59 that the process of water supply to the sub-areas causing shrinkage of water resources in the basin

60 area, thus, in order to have a long-term vision of the water supply process and to verify that the

61 system is sustainable, in practice, it is vital to propose an optimal framework to improve the

62 sustainability of system. In general, the sustainability measure evaluates water management

63 policies according to the system performance indices intending to investigate the integrated

64 behavior of the system, taking into account possible adverse consequences such as imbalance

65 between supply and demand (Loucks 1997; Sandoval-Solis et al. 2011). However, according to

66 the above descriptions, the main contributions of this study are listed below:

67 1) A dynamic optimization framework has been proposed to cope with drought in the long-

68 term water supply process and to evaluate the system sustainability measure in different 69 sectors.

70 2) Due to the uncertainty in the supply process, different scenarios of water demand and water 71 supply are applied as a management perspective for reviewing and analyzing periodic 72 decisions. 
74 The remainder of this paper is organized as follows. Section 2 develops the framework of this

75 study and case study. Section 3 expands dynamic optimization model. Section 4 proposes study

76 area and data collection. Section 5 includes results and analysis. Section 6 gives concluding

77 remarks.

78

\section{2. Framework of indices impacting on sustainability of system during water}

80 supply process

81 In general, the sustainability of a water supply system is a reflection of an adaptive operational

82 approach in which the decision maker adjusts system performance based on the amount of 83 available water resources in a given period (Ajami et al. 2008). Indeed, the optimal performance 84 of system in the long run, regarding limited resources, reflects the improvement of system 85 sustainability, so that a performing system is also considered as a sustainable system (Fechete and 86 Nedelcu 2019). Thus, the sustainability of the water supply system is the integration of 87 performance indicators (as shown in Fig.1) that are adaptive features of the system for the use of 88 available water resources and, in fact summarizes the alternative performance of the system from 89 the perspective of consumers in a given period (Sandoval-Solis et al. 2011). 


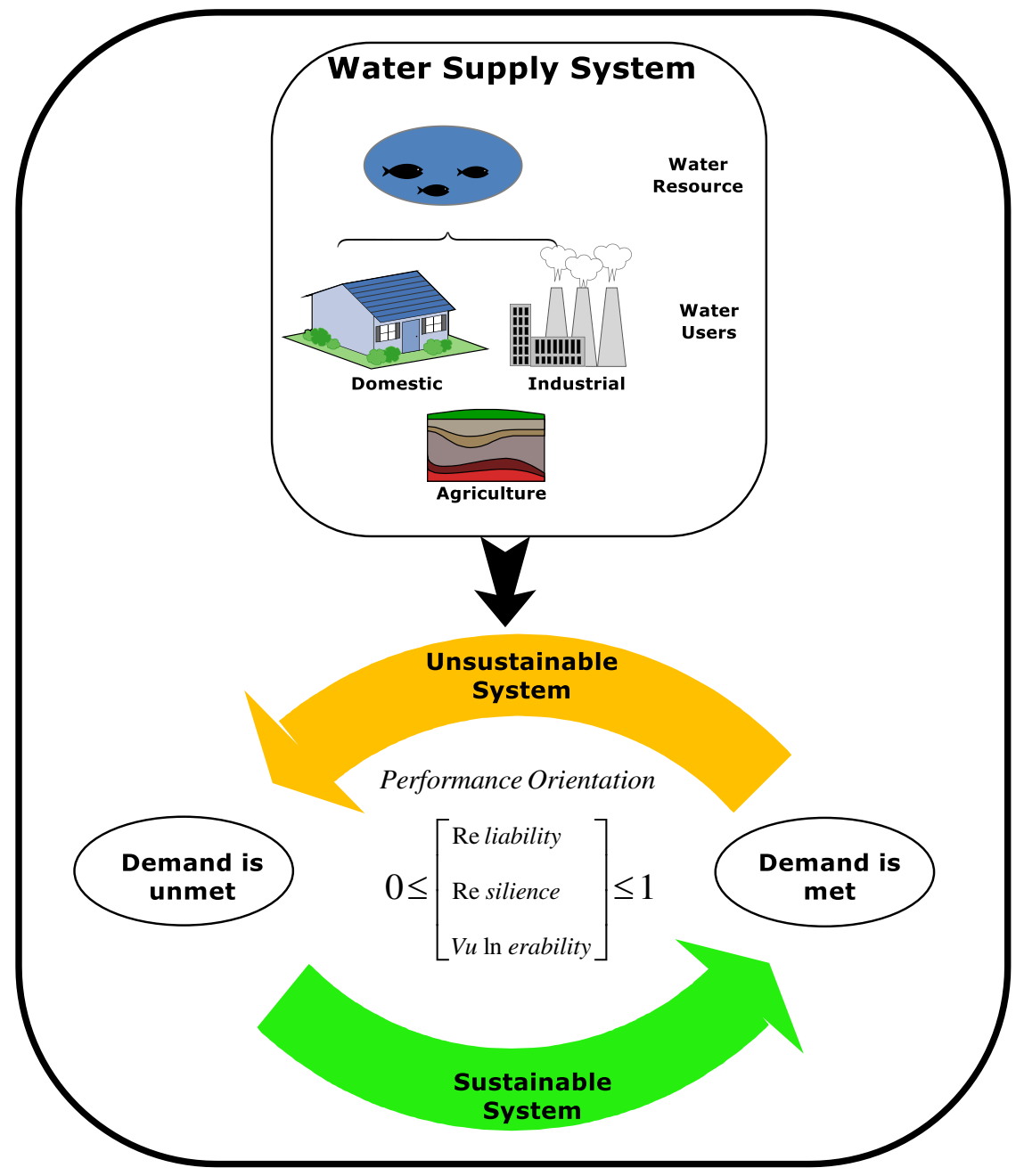

Fig.1. Framework of water supply system in terms of optimal sustainable development

95 To this end, the definition provided for the sustainability measure of the water supply system is as 96 follow (Karamouz et al. 2017; Loucks 1997):

$$
S_{t}^{j}=\eta_{t}^{j} * \lambda_{t}^{j} *\left(1-\beta_{t}^{j}\right)
$$

98 Where, $S_{t}^{j}$ is defined as value of the sustainability, $\eta_{t}^{j}$ is reliability index, $\lambda_{t}^{j}$ refers to resilience 99 indicator, and $\beta_{t}^{j}$ is vulnerability index related to sector $j$ in period $t$. Indeed, reliability, resilience, 
100

101

102

103

104

105

106

107

108

109

110

111

112

113

114

115

116

and vulnerability are considered as performance indices of water supply system (Gu et al. 2017;

Hashimoto et al. 1982), which are calculated as follows:

\subsection{Reliability}

By definition, reliability of system is the probability that satisfactory state of system will remain unchanged for a certain time. Thus, water supply system reliability is measured by whether the system meets a predetermined demand criterion and if not, what rate of the demand is met during the simulated period (Hashimoto et al. 1982; Ajami et al. 2008; Maestro et al. 2014):

$$
\eta_{t}^{j}=\frac{1}{T} \sum_{t-1}^{T}\left(1-\mu_{t}^{j}\right) \quad t=1, \ldots, T \text { and } j=1, \ldots, m
$$

Where, $\mu_{t}^{j}$ treats as a binary variable (0 and 1), so that if the requested demand is supplied in period t, then the system is satisfied, so $\mu_{t}^{j}=0$, and vice versa, if there is water shortage $\mu_{t}^{j}=1$.

However, the high value of the $\eta_{t}^{j}$ index indicates the high reliability of water supply system.

\subsection{Resilience}

Resilience refers to the probability that a system will improve from a failure state to an UN failure state. Therefore, the resilience of the water supply system for sector $j$ is referred to as the probability that the system will not experience water shortage during the simulated period (Asefa et al. 2014; Hashimoto et al. 1982):

$$
\lambda_{t}^{j}=\frac{\sum_{t=1}^{T} \rho_{t}^{j}}{T-\sum_{t=1}^{T} \mu_{t}^{j}}
$$

117 Where $\rho_{t}^{j}$ is defined as the transition between failure and UN failure modes in the given period 118 whose value is 1 or 0 :

$$
\rho_{t}^{j}= \begin{cases}1 & \text { if } y_{t-1}^{j} \in \text { failure and } y_{t}^{j} \in U N \text { failure } \\ 0 & \text { Others }\end{cases}
$$


120 It needs to mention that $y_{t}^{j}$ is referred to a given time series of a parameter of interest.

121

$122 \quad 2.3$ Vulnerability

123 The vulnerability of a system is referred to probability value of failures in the simulated period 124 (Sandoval-Solis et al. 2011). By definition, the vulnerability of the water supply system indicates 125 the average of maximum shortages at all failure times (Goharian et al. 2017; Hashimoto et al. 1982; 126 Gu et al. 2017):

127

$$
\beta_{t}^{j}=\frac{1}{T_{V}^{j}} \sum_{t=1}^{T} \frac{z_{t}^{j} * R_{t}^{j}}{D_{t}^{j}}
$$

$$
T_{v}^{j}=\sum_{t=1}^{T} \sum_{j=1}^{m} z_{t}^{j}
$$

In addition, the definition of water shortage in period $t$ is as follows:

$$
R_{t}= \begin{cases}\sum_{j=1}^{m} D_{t}^{j}-\sum_{j=1}^{m} x_{t}^{j}, & \left.\sum_{j=1}^{m} D_{t}^{j}\right\rangle \sum_{j=1}^{m} x_{t}^{j} \\ 0 \quad & \sum_{j=1}^{m} D_{t}^{j}\left\langle\sum_{j=1}^{m} x_{t}^{j}\right.\end{cases}
$$

134 However, the rate of water shortage in sector $j$ depends on the gap between the amount of water 135 demand $D_{t}^{j}$ and water supply $x_{t}^{j}$ in period $t$.

\section{Dynamic optimization model}

137 Based on the applied long-term evaluation framework, a dynamic model is proposed to optimize 138 the sustainability of the water supply system in a given period. 
141 The volume of water in the reservoir based on the volume of water availability related to the prior 142 period and the rate of runoff is defined as below:

$$
l_{t}=\min \left[l_{t-1}-\sum_{j=1}^{m} x_{t}^{j}+I_{t}, \bar{l}\right]
$$

144 Where, $l_{t-1}$ is the volume of available water in the reservoir in period $t-1, I_{t}$ is the rate of runoff 145 during the period $t$, and $\bar{l}$ is referred to the maximum capacity of the reservoir.

146 Besides, the amount of water allocated to different sectors must be less than the amount of water 147 in the reservoir:

$$
0 \leq \sum_{j=1}^{m} x_{t}^{j} \leq l_{t}
$$

149 In addition, the volume of water transferred to sub-areas must be less than the amount of available 150 water in the reservoirs:

$$
l_{t}^{\min } \leq l_{t} \leq \bar{l}
$$

152 However, the global dynamic model of this study to reduce the impacts of drought on the water 153 supply system and maximizing the level of sustainability in the optimal system is as follow: 
$\max F=\eta_{t}^{j} * \lambda_{t}^{j} *\left(1-\beta_{t}^{j}\right)$

$$
\begin{aligned}
& \eta_{t}^{j}=\frac{1}{T} \sum_{t=1}^{T}\left(1-\mu_{t}^{j}\right) \quad t=1, \ldots, T \text { and } j=1, \ldots, m \\
& \lambda_{t}^{j}=\frac{\sum_{t=1}^{T} \rho_{t}^{j}}{T-\sum_{t=1}^{T} \mu_{t}^{j}} \\
& \beta_{t}^{j}=\frac{1}{T_{V}^{j}} \sum_{t=1}^{T} \frac{z_{t}^{j} * R_{t}^{j}}{D_{t}^{j}} \\
& T_{v}^{j}=\sum_{t=1}^{T} \sum_{j=1}^{m} z_{t}^{j} \\
& R_{t}= \begin{cases}\sum_{j=1}^{m} D_{t}^{j}-\sum_{j=1}^{m} x_{t}^{j}, & \left.\sum_{j=1}^{m} D_{t}^{j}\right\rangle \sum_{j=1}^{m} x_{t}^{j} \\
0 \quad, & \sum_{j=1}^{m} D_{t}^{j}\left\langle\sum_{j=1}^{m} x_{t}^{j}\right.\end{cases} \\
& l_{t}=\min \left[l_{t-1}-\sum_{j=1}^{m} x_{t}^{j}+I_{t}, \bar{l}\right] \\
& 0 \leq \sum_{j=1}^{m} x_{t}^{j} \leq l_{t} \\
& l_{t}^{\min } \leq l_{t} \leq \bar{l} \\
& \left\{\begin{array}{l}
\rho_{t}^{j}= \begin{cases}1 & \text { if } y_{t-1}^{j} \in \text { failure and } y_{t}^{j} \in U N \text { failure } \\
0 & \text { Others }\end{cases} \\
w_{\eta}+w_{\lambda}+w_{\beta}=1
\end{array}\right.
\end{aligned}
$$

\section{Case study and data collection}

156 The Sistan Basin $\left(30^{\circ}-31.5^{\circ} \mathrm{N}\right.$ to $\left.61^{\circ}-66^{\circ} \mathrm{E}\right)$, also known as Hamoon watershed, is located in

157 Sistan and Baluchestan province of Iran near the border of Iran-Afghanistan. In recent years, due

158 to the arid climatic conditions of the region and the reduction of the average annual rainfall (60

$159 \mathrm{~mm}$, which occurs mainly in winter) on the one hand, and operating of successive dams on the Helmand River as the main source of water supply in this basin, on the other hand, the drought

161 situation has become extremely acute (He at al. 2021; Najafi, and Vatanfada 2011).For mentioned

162 reasons, the decision-makers to manage the water demand of the two sub-areas of Zabol and 
Zahedan, diverted the runoff flowing to Helmand river to the Chahnimeh reservoirs (Yao et al. 2019). But recently, with the intensification of drought and shrinking of water resources, decision makers have been unable to maintain the deviation between water demand and water supply different sectors, so this study considered the Sistan basin as a the study area (Fig.2).

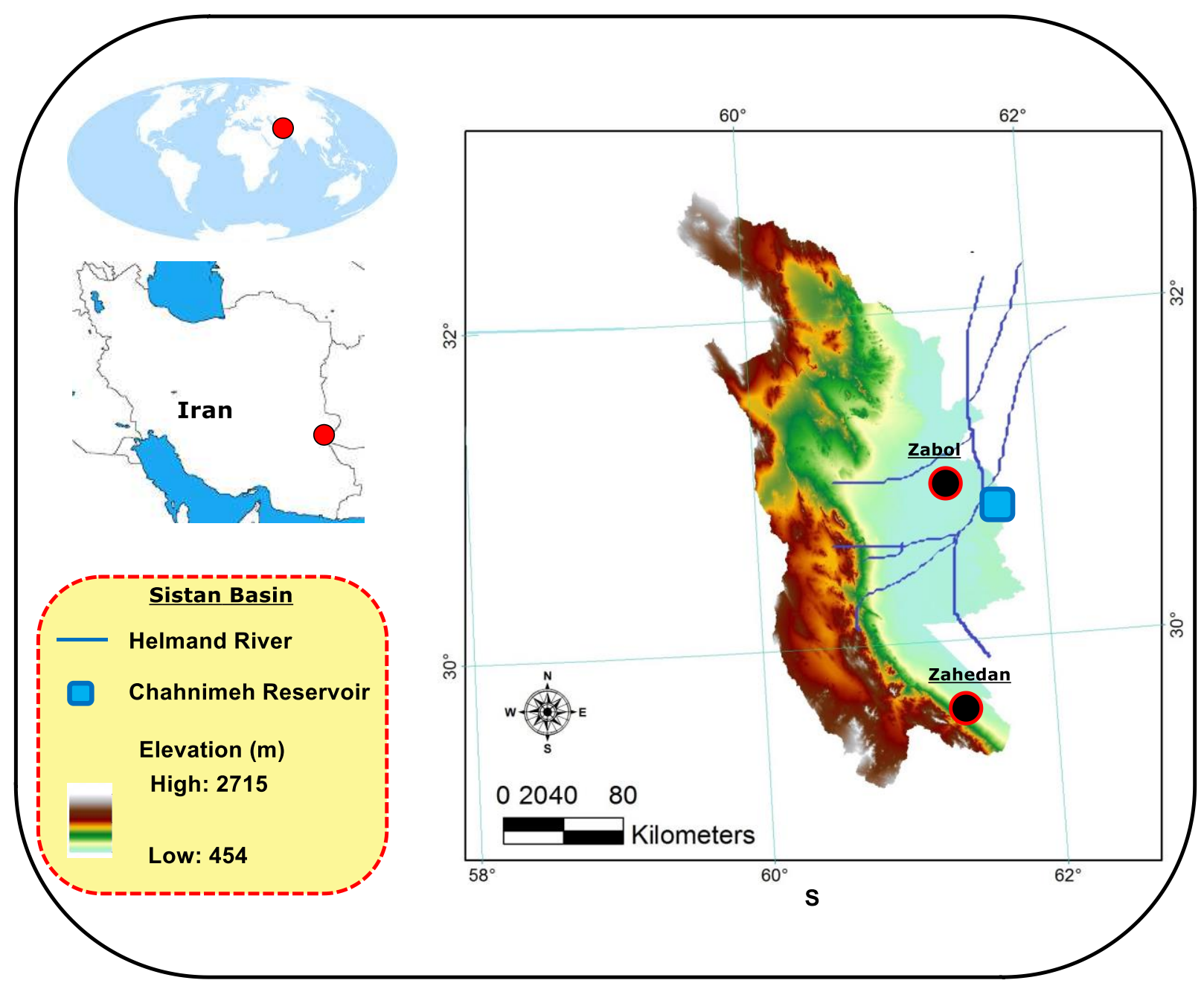

Fig.2. Sistan Basin location, Iran

169 Therefore, the data related to the capacity of reservoirs and the amount of runoff are derived from the Bulletin of Regional Water Department of the Sistan and some citations (Thomas and Varzi 171 2015; Yao et al. 2019; He et al. 2021). Besides, data on water demand for the three sectors of 
172 agricultural, industrial, and domestic are extracted from statistical Bulletin registered with the

173 Sistan and Baluchestan Regional Water Authority Department.

174

175 Table 1

176 Parameter of water demand in sub-areas

\begin{tabular}{|c|c|c|c|c|c|c|c|c|c|c|c|}
\hline $\mathbf{j}$ & & 2008 & 2009 & 2010 & 2011 & 2012 & 2013 & 2014 & 2015 & 2016 & 2017 \\
\hline \multirow{3}{*}{$\begin{array}{l}\text { Zabol } \\
\left(10^{6} \mathbf{m}^{3}\right)\end{array}$} & AGR & 49.17 & 52.65 & 50.82 & 52.00 & 55.62 & 53.31 & 53.92 & 50.47 & 57.05 & 56.43 \\
\hline & IND & 11.58 & 10.86 & 12.09 & 13.29 & 13.01 & 16.93 & 14.78 & 13.41 & 15.23 & 16.11 \\
\hline & DOM & 5.16 & 6.17 & 6.64 & 7.14 & 6.48 & 7.86 & 7.32 & 8.44 & 9.27 & 9.84 \\
\hline \multirow{3}{*}{$\begin{array}{c}\text { Zahedan } \\
\left(10^{6} \mathrm{~m}^{3}\right)\end{array}$} & AGR & 24.38 & 23.79 & 21.85 & 24.07 & 25.21 & 27.69 & 28.41 & 28.17 & 29.57 & 31.71 \\
\hline & IND & 33.14 & 35.16 & 43.79 & 37.19 & 41.56 & 42.27 & 41.96 & 44.40 & 43.16 & 45.78 \\
\hline & DOM & 19.43 & 21.14 & 22.68 & 23.36 & 24.08 & 23.76 & 27.50 & 32.33 & 25.64 & 28.53 \\
\hline \multicolumn{2}{|c|}{ Streamflow $_{\left(\mathbf{m}^{3} \mathbf{s}^{-1}\right)}$} & 6.23 & 5.96 & 5.38 & 6.87 & 6.16 & 5.75 & 4.89 & 6.03 & 5.46 & 5.74 \\
\hline
\end{tabular}

- $\mathrm{AGR}=$ Agricultural sector, $\mathrm{IND}=$ Industrial sector, $\mathrm{DOM}=$ Domestic sector

Table 2

180 Reservoirs Parameters in the basin $\left(10^{6} \mathrm{~m}^{3}\right)$

\begin{tabular}{lcccccc}
\hline Reservoirs & Chahnimeh 1 & Chahnimeh 2 & Chahnimeh 3 & Chahnimeh 4 & Zabol & Zahedan \\
\hline Dead storage & 51.22 & 36.29 & 39.65 & 89.58 & 16.23 & 23.16 \\
Active storage & 139.28 & 107.67 & 128.73 & 337.86 & 43.35 & 51.47 \\
Total storage & 220.00 & 220.00 & 220.00 & 820.00 & 155.00 & 155.00 \\
\hline
\end{tabular}

\section{Model results and analysis}

\subsection{Adopted optimal water supply to sub-sectors}

Table 3 are listed the optimal outputs related to water allocation between sectors of the two sub-

areas. According to the output, the amount of water allocated to the agricultural sector in Zabol is

191 with a value equal to $30.19 * 10^{6} \mathrm{~m}^{3}$. 
192 By analysis of system sustainability (as shown in Table 4), the domestic sector has acquired the 193 highest value for both sub-areas $(0.491,0.389)$ since the status of this sector in all three factors of 194 reliability, resilience (resilience factor has not changed because the status of the system did not 195 alter from failure to UN failure), and vulnerability is better than other two sectors.

197 Table. 3

198 Optimal water allocated to sectors $\left(10^{6} \mathrm{~m}^{3}\right)$

\begin{tabular}{|c|c|c|c|c|c|c|c|c|c|c|c|}
\hline$x_{t}^{j}$ & & 2008 & 2009 & 2010 & 2011 & 2012 & 2013 & 2014 & 2015 & 2016 & 2017 \\
\hline \multirow{3}{*}{ Zabol } & AGR & 47.36 & 48.17 & 49.74 & 50.53 & 52.09 & 51.87 & 50.34 & 49.49 & 56.59 & 54.12 \\
\hline & IND & 10.13 & 09.72 & 10.67 & 11.58 & 12.28 & 14.38 & 13.58 & 12.17 & 14.37 & 15.27 \\
\hline & DOM & 4.79 & 5.36 & 5.14 & 6.28 & 5.87 & 6.41 & 6.18 & 7.17 & 8.59 & 7.79 \\
\hline \multirow{3}{*}{ Zahedan } & AGR & 19.76 & 21.08 & 19.39 & 22.53 & 23.78 & 26.02 & 25.94 & 27.49 & 26.76 & 28.34 \\
\hline & IND & 32.35 & 33.64 & 40.73 & 36.01 & 39.00 & 40.92 & 39.81 & 42.14 & 42.68 & 44.46 \\
\hline & DOM & 18.19 & 20.04 & 21.36 & 22.14 & 23.36 & 22.61 & 25.71 & 30.19 & 24.28 & 27.09 \\
\hline
\end{tabular}

Table 4

202 Analysis of sustainability measure

\begin{tabular}{|c|c|c|c|c|c|c|c|c|c|c|c|c|}
\hline & \multicolumn{3}{|c|}{ Reliability } & \multicolumn{3}{|c|}{ Resilience } & \multicolumn{3}{|c|}{ Vulnerability } & \multicolumn{3}{|c|}{ Sustainability } \\
\hline & AGR & IND & DOM & AGR & IND & DOM & AGR & IND & DOM & AGR & IND & DOM \\
\hline \multirow[t]{2}{*}{ Zabol } & 0.2 & 0.4 & 0.4 & 1 & 1 & 1 & 0.036 & 0.028 & 0.019 & 0.192 & 0.388 & 0.491 \\
\hline & \multicolumn{3}{|c|}{$\mathrm{DOM}=\mathrm{IND}>\mathrm{AGR}$} & \multicolumn{3}{|c|}{$\mathrm{DOM}=\mathrm{IND}=\mathrm{AGR}$} & \multicolumn{3}{|c|}{ AGR $>$ IND $>$ DOM } & \multicolumn{3}{|c|}{$\mathrm{DOM}>\mathrm{IND}>\mathrm{AGR}$} \\
\hline \multirow[t]{2}{*}{ Zahedan } & 0.3 & 0.2 & 0.4 & 1 & 1 & 1 & 0.029 & 0.030 & 0.026 & 0.194 & 0.194 & 0.389 \\
\hline & \multicolumn{3}{|c|}{$\mathrm{DOM}>\mathrm{AGR}>\mathrm{IND}$} & \multicolumn{3}{|c|}{$\mathrm{DOM}=\mathrm{IND}=\mathrm{AGR}$} & \multicolumn{3}{|c|}{$\mathrm{IND}>\mathrm{AGR}>\mathrm{DOM}$} & \multicolumn{3}{|c|}{$\mathrm{DOM}>\mathrm{IND}=\mathrm{AGR}$} \\
\hline
\end{tabular}

204 In addition, Figure 3 shows an analysis maintaining the deviation between the total volume of 205 water supplied to each sub-areas and total water demand. Based on the final output, the maximum 206 gap between water demand and water supply for Zahedan city was experienced in 2008 and 2010 207 with water supply rate of $70.30 * 10^{6} \mathrm{~m}^{3}$ and $81.48 * 10^{6} \mathrm{~m}^{3}$ and water demand equal to $76.95 *$ $20810^{6} \mathrm{~m}^{3}$ and $88.32 * 10^{6} \mathrm{~m}^{3}$, respectively, while this rate for Zabol city is related to 2009 and 2013 
with a value equal to $63.25 * 10^{6} \mathrm{~m}^{3}$ and $72.66 * 10^{6} \mathrm{~m}^{3}$ for the supply side and $69.98 * 10^{6} \mathrm{~m}^{3}$ and $78.10 * 10^{6} \mathrm{~m}^{3}$ for the demand side. Although the optimal process of water supply has

211 reduced the deviation between water demand and water supply, due to increasing demand for water

212 regarding population growth and also reducing runoff rates in the Sistan basin, the unsustainability 213 of the water supply system is still prominent.

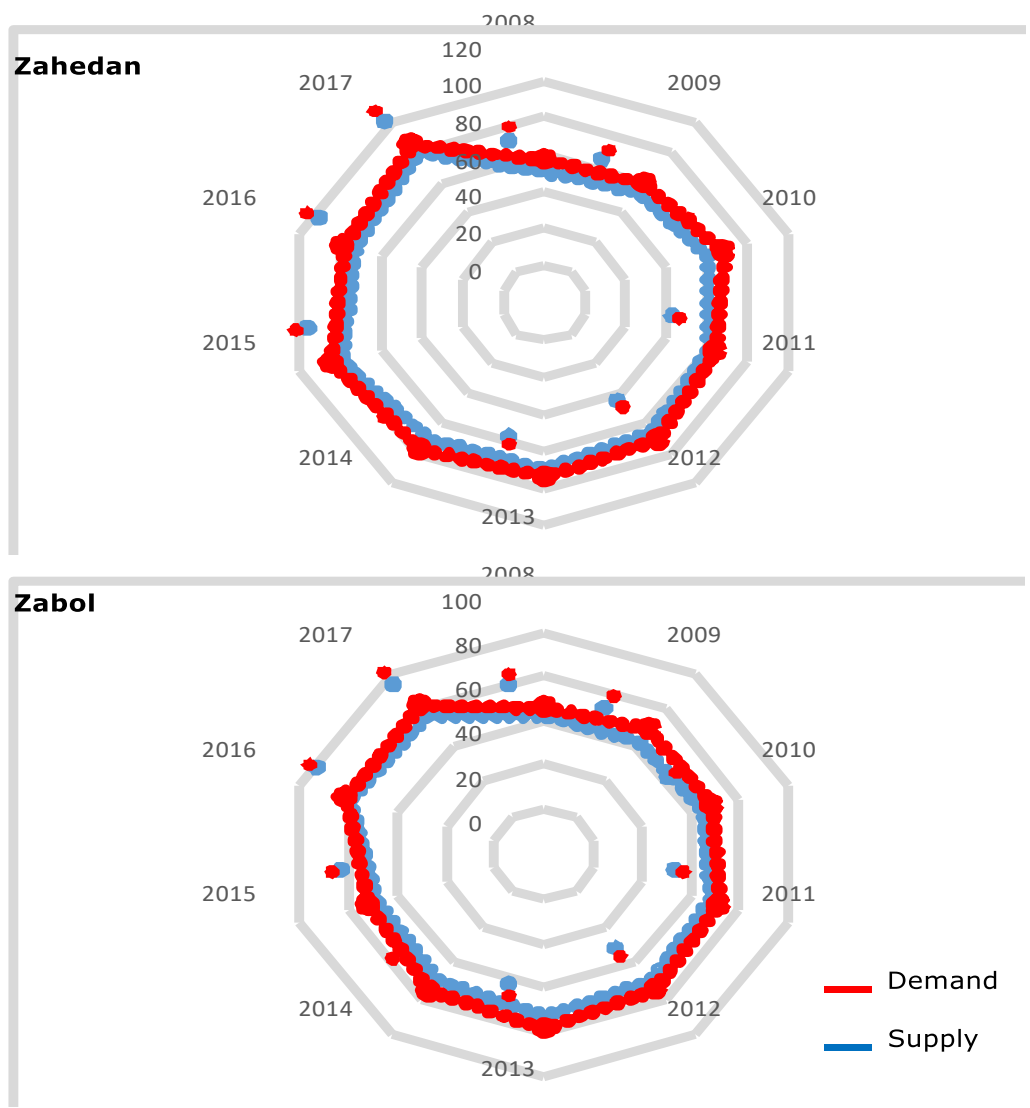

\section{$217 \quad 5.2$ Scenario analysis of sustainability measure in water supply procedure}

218 Given that water supply measures in the upcoming years are influenced by uncertainty in the

219 volume of runoff, therefore, scenario analysis method proposed by Xu et al. (2019) is considered 220 to analyze the sustainability of water supply system. Indeed, according to historical runoff data, 
221 the two new scenarios, streamflow rate $90 \%$ and $70 \%$ of current runoff rate, are considered to

222 provide an optimal solution and to assess sustainability measure.

223 Table 5

224 Scenario analysis of water supply

\begin{tabular}{cclccccccccccc}
\hline j & $\boldsymbol{I}_{\boldsymbol{t}}$ & & $\mathbf{2 0 0 8}$ & $\mathbf{2 0 0 9}$ & $\mathbf{2 0 1 0}$ & $\mathbf{2 0 1 1}$ & $\mathbf{2 0 1 2}$ & $\mathbf{2 0 1 3}$ & $\mathbf{2 0 1 4}$ & $\mathbf{2 0 1 5}$ & $\mathbf{2 0 1 6}$ & $\mathbf{2 0 1 7}$ & $\mathbf{2 0 1 8}$ \\
\hline \multirow{3}{*}{ Zabol } & & AGR & 46.19 & 46.96 & 47.41 & 45.5 & 49.33 & 49.56 & 46.59 & 49.93 & 54.62 & 54.24 & 46.19 \\
& & IND & 9.00 & 9.36 & 8.52 & 10.84 & 12.07 & 10.6 & 10.71 & 12.47 & 13.99 & 13.26 & 9.00 \\
& $-10 \%$ & DOM & 3.82 & 5.37 & 5.03 & 5.46 & 3.69 & 6.88 & 5.5 & 5.79 & 7.37 & 6.92 & 3.82 \\
Zahedan & & AGR & 18.79 & 19.45 & 17.86 & 21.39 & 23.87 & 25.42 & 25.23 & 26.63 & 23.5 & 24.57 & 18.79 \\
& & IND & 31.96 & 33.11 & 38.85 & 36.1 & 41.73 & 41.31 & 42.09 & 42.89 & 41.71 & 43.99 & 31.96 \\
& & DOM & 20.19 & 22.44 & 22.98 & 23.46 & 24.77 & 20.52 & 26.68 & 28.17 & 25.99 & 26.61 & 20.19 \\
Zabol & & & & & & & & & & & & & \\
& & AGR & 46.53 & 46.96 & 45.02 & 45.63 & 47.58 & 49.13 & 45.68 & 49.69 & 55.78 & 52.86 & 46.53 \\
& & IND & 8.41 & 10.36 & 7.57 & 9.73 & 10.87 & 9.39 & 9.15 & 12.81 & 12.27 & 11.96 & 8.41 \\
Zahedan & $-30 \%$ & DOM & 4.29 & 4.93 & 4.62 & 4.38 & 3.69 & 5.66 & 5.82 & 5.13 & 7.5 & 6.51 & 4.29 \\
& & AGR & 17.76 & 18.39 & 17.02 & 21.61 & 23.12 & 24.33 & 22.97 & 26.53 & 22.42 & 23.97 & 17.76 \\
& & IND & 32.21 & 33.67 & 37.25 & 34.94 & 40.56 & 42.1 & 40.98 & 41.64 & 41.71 & 42.28 & 32.21 \\
& & DOM & 18.81 & 20.65 & 21.43 & 22.58 & 23.61 & 20.32 & 25.29 & 26.92 & 26.64 & 26.03 & 18.81 \\
\hline
\end{tabular}

225

226 By comparing the outputs listed in Table 5 with Table 3, the deviation between water demand and

227 water supply for the domestic sector under the following scenarios is slightly different, while this

228 value for the other two sectors, as the largest water recipient sectors, has further deviated.

229 In addition, according to the analysis of sustainability measure indicated in Figure 5, in the first

230 scenario (reduced runoff by $-10 \%$ ), the minimum rate of sustainability in Zabol and Zahedan is

231 related to the agricultural sector with values $(0.1932,0.1946)$ respectively, while for the second

232 scenario (reduced runoff by $-30 \%$ ), the minimum sustainability is related to the industrial sector

233 with values equal to (0.1954 and 0.0972) for the two cities of Zabol and Zahedan, which means

234 these two sectors are the most sensitive sectors in terms of sustainable development. Also, the

235 domestic sector, which had less water demand than the other two sectors, had maximum

236 sustainability in both scenarios. 


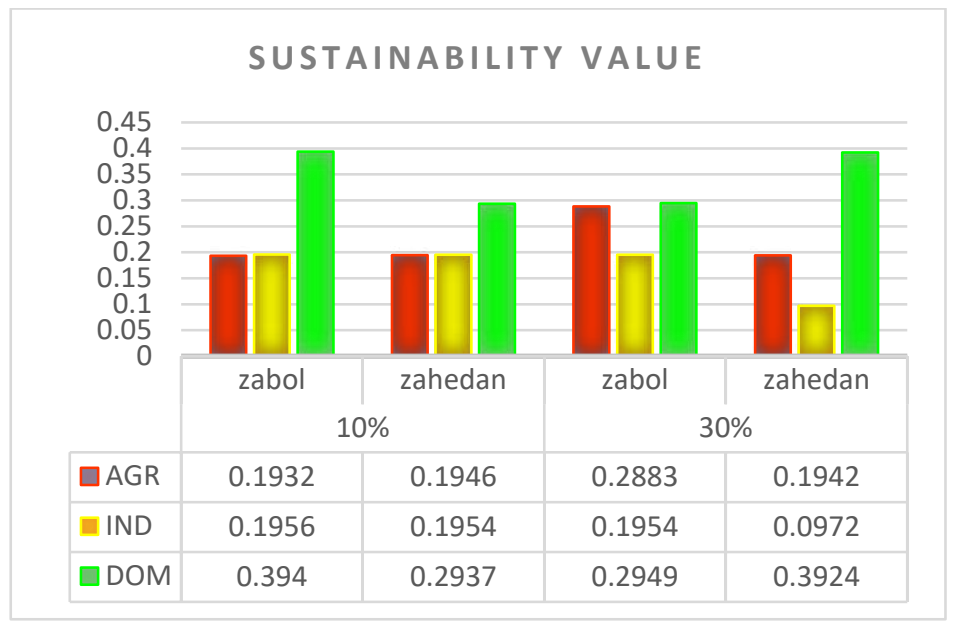

5.3 Adjusted strategies for analysis of sustainability measure under demand shrinkage scenarios

242 According to recent studies (Najafi and Vatanfada 2011; Moghaddamnia et al. 2009; Yao et al. 2019), the Sistan basin will experience rainfall reduction and temperature rising, which means that the situation of water resources will be more limited. On the other hand, the increase in demand for water due to population growth causes the expansion to deviate between the demand for water 246 and water supply. However, adaptation measures for water supply focus on proposing water 247 distribution policies and strategies between different sectors and neglect the development of water 248 demand management options. To this end, proposing practical managerial insights compatible with 249 the current situation, such as the development of leverage policies such as tariffs for water, the use 250 of advanced technologies to reduce demand for water, such as the development of drip irrigation 251 systems, treatment and reuse of wastewater, can be alternatively effective for conserving water 252 resources. Thus, this study applies the demand shrinkage scenarios ( at $10 \%$ and $20 \%$ less than the 253 actual demand) proposed by He et al. (2021) to evaluate the sustainability of the water supply 254 system. 
255 According to the output listed in Table 6, the reliability and resilience of all three agricultural, 256 industrial, and domestic sectors show an improvement compared to Table 4, but the value of the 257 vulnerability factor for all three sectors has not changed much. In general, with the improvement 258 of these factors, the sustainability of the system has become more optimal than before.

Table 6

261 The impact of demand shrinkage scenarios on sustainability measure

\begin{tabular}{|c|c|c|c|c|c|c|c|c|c|c|c|c|c|}
\hline \multirow[b]{2}{*}{$\mathrm{j}$} & \multirow{2}{*}{$\begin{array}{l}\text { Demand } \\
\text { shrinkage }\end{array}$} & \multicolumn{3}{|c|}{ Reliability } & \multicolumn{3}{|c|}{ Resilience } & \multicolumn{3}{|c|}{ Vulnerability } & \multicolumn{3}{|c|}{ Sustainability } \\
\hline & & AGR & IND & DOM & AGR & IND & DOM & AGR & IND & DOM & AGR & IND & DOM \\
\hline Zabol & $10 \%$ & 0.3 & 0.5 & 0.6 & 1 & 1 & 0.2 & 0.040 & 0.035 & 0.015 & 0.288 & 0.482 & 0.591 \\
\hline Zahedan & & 0.4 & 0.6 & 0.6 & 1 & 0.2 & 1 & 0.033 & 0.037 & 0.028 & 0.387 & 0.578 & 0.583 \\
\hline Zabol & $20 \%$ & 0.7 & 0.5 & 0.5 & 0.2 & 0.4 & 0.5 & 0.041 & 0.026 & 0.017 & 0.671 & 0.487 & 0.492 \\
\hline Zahedan & & 0.5 & 0.6 & 0.7 & 0.2 & 0.3 & 0.6 & 0.032 & 0.039 & 0.021 & 0.484 & 0.672 & 0.587 \\
\hline
\end{tabular}

\subsection{Discussion}

264 In general, due to climate change, the water crisis problem is becoming more acute, which can be minimized with proper planning. While the multi-sectoral users in sub-areas request different volumes of water by different priorities, the development of new adaptive measures to prioritize water supply between key sectors can increase system sustainability. Besides, in areas such as Sistan, which is highly dependent on the volume of runoff, proposing managerial insights is very

269 effective in reserving available waters. In this regard, the rate of water consumption depends on 270 the rate of population (Of Sciences 1999), so that increasing population and the need for food, 271 would increase consumption of fresh water. Therefore, strategic simulation of population 272 distribution patterns in order to analyze water demand, development of more efficient irrigation 273 systems, and alteration of crop patterns, etc. can help to better manage the limited water resources. 274 However, according to the above description, the superiority of the proposed model is as follows:

1) The proposed framework in this study is a practical mechanism to optimize the water supply system at the regional scale and improve sustainability under different scenarios in 
an uncertain environment, which provides a long-term perspective to the basin authorities and facilitates the planning of limited water resources in order to maximize the sustainability of system.

2) To minimize the impacts of runoff uncertainty on the optimal water supply process, the development of appropriate adaptive measures to maintain the deviation between water supply and water demand is effective. To this end, a sole focus on water resources management does not lead to adaptation, and the development of new policies such as demand shrinkage scenarios can lead to increased long-term system sustainability.

\section{Conclusion}

Since the sustainability of the water supply system depends on the status of regional water resources, this study proposed an optimal framework for the sustainability of water supply system between three sectors in an uncertain environment. In fact, an assessment index was applied for the sustainable development of the system, to analyze shortage in the regional water supply system based on the performance indicators. Also, a case study from Iran was proposed to examine the developed model. However, this study lists the following recommendations based on the outputs: 1) Based on the degree of drought, decision makers can first distinguish the more sensitive sectors according to the objective function and then allocate water to each of these sectors according to their priority for system sustainability. 2) Sustainable water conservation and mitigation of drought impacts require the development of innovations that are compatible with the severity of the water crisis in the sectors that receive the most water. 3) Given that the uncertainty of climate change has not been proposed in this study, projecting the climate change patterns to examine the scale and amount of runoff and then planning for optimal water allocation in the basin area can lead to the development of strategic management of system sustainability. 4) Finally, the expansion of 

system vulnerability reflects sustainable system development.

\section{Declarations}

304

305 Availability of data and material

306 Not applicable.

307 Competing Interests

308 Not applicable.

309 Funding

310 Not applicable.

311

312

\section{Authors' contributions}

313 Not applicable.

314 Acknowledgements

315 Not applicable.

References

1) Abdi-Dehkordi M, Bozorg-Haddad O, Chu X. Development of a Combined Index to Evaluate Sustainability of Water Resources Systems. Water Resources Management. 2021 Jul;35(9):2965-85.

2) Asefa T, Clayton J, Adams A, Anderson D. Performance evaluation of a water resources system under varying climatic conditions: Reliability, Resilience, Vulnerability and beyond. Journal of Hydrology. 2014 Jan 16;508:53-65.

3) Ajami NK, Hornberger GM, Sunding DL. Sustainable water resource management under hydrological uncertainty. Water Resources Research. 2008 Nov;44(11).

4) Brown CM, Lund JR, Cai X, Reed PM, Zagona EA, Ostfeld A, Hall J, Characklis GW, Yu $\mathrm{W}$, Brekke L. The future of water resources systems analysis: Toward a scientific 
framework for sustainable water management. Water resources research. 2015 Aug;51(8):6110-24.

5) Butler D, Ward S, Sweetapple C, Astaraie-Imani M, Diao K, Farmani R, Fu G. Reliable, resilient and sustainable water management: the Safe \& SuRe approach. Global Challenges. 2017 Jan;1(1):63-77.

6) Chen Y, He L, Lu H, Li J, Ren L. Planning for regional water system sustainability through water resources security assessment under uncertainties. Water Resources Management. 2018 Jul;32(9):3135-53.

7) Fechete F, Nedelcu A. Performance management assessment model for sustainable development. Sustainability. 2019 Jan;11(10):2779.

8) Gu W, Shao D, Tan X, Shu C, Wu Z. Simulation and optimization of multi-reservoir operation in inter-basin water transfer system. Water resources management. 2017 Sep;31(11):3401-12.

9) Goharian E, Burian SJ, Lillywhite J, Hile R. Vulnerability assessment to support integrated water resources management of metropolitan water supply systems. Journal of Water Resources Planning and Management. 2017 Mar 1;143(3):04016080.

10) He Y, Mahdi M, Huang P, Xie G, Galoie M, Shafi M. Investigation of Climate Change Adaptation Impacts on Optimization of Water Allocation Using a Coupled SWAT-bi Level Programming Model. Wetlands. 2021 Mar;41(3):1-8.

11) Hashimoto T, Stedinger JR, Loucks DP. Reliability, resiliency, and vulnerability criteria for water resource system performance evaluation. Water resources research. 1982 Feb;18(1):14-20.

12) Jun KS, Chung ES, Sung JY, Lee KS. Development of spatial water resources vulnerability index considering climate change impacts. Science of the total environment. $2011 \mathrm{Nov}$ 15;409(24):5228-42.

13) Karamouz M, Mohammadpour P, Mahmoodzadeh D. Assessment of sustainability in water supply-demand considering uncertainties. Water Resources Management. 2017 Sep;31(12):3761-78.

14) Loucks DP. Quantifying trends in system sustainability. Hydrological Sciences Journal. 1997 Aug 1;42(4):513-30. 
15) Maestro T, Nicolosi V, Cancelliere A, Bielza M. Impacts of climate change, hydrological drought mitigation measures and irrigation demand on water supply system performance. Eur Water. 2014;45(46):25-33.

16) Moghaddamnia A, Gousheh MG, Piri J, Amin S, Han D. Evaporation estimation using artificial neural networks and adaptive neuro-fuzzy inference system techniques. Advances in Water Resources. 2009 Jan 1;32(1):88-97.

17) Najafi A, Vatanfada J. Environmental challenges in trans-boundary waters, case study: Hamoon Hirmand Wetland (Iran and Afghanistan). International Journal of Water Resources and Arid Environments. 2011;1(1):16-24.

18) of Sciences IA. Water for the Future: The West Bank and Gaza Strip, Israel, and Jordan.

19) Rathnayaka K, Malano H, Arora M. Assessment of sustainability of urban water supply and demand management options: a comprehensive approach. Water. 2016 Dec;8(12):595.

20) Ryu JH, Palmer RN, Jeong S, Lee JH, Kim YO. Sustainable Water Resources Management in a Conflict Resolution Framework 1. JAWRA Journal of the American Water Resources Association. 2009 Apr;45(2):485-99.

21) Srdjevic Z, Srdjevic B. An extension of the sustainability index definition in water resources planning and management. Water Resources Management. 2017 Mar $1 ; 31(5): 1695-712$.

22) Sandoval-Solis S, McKinney DC, Loucks DP. Sustainability index for water resources planning and management. Journal of water resources planning and management. 2011 Sep 1;137(5):381-90.

23) Thomas V, Varzi MM. A legal licence for an ecological disaster: the inadequacies of the 1973 Helmand/Hirmand water treaty for sustainable transboundary water resources development. International Journal of Water Resources Development. 2015 Oct 2;31(4):499-518.

24) Waite M. Sustainable water resources in the built environment. IWA Publishing; 2010 Apr 29.

25) Xiong W, Li Y, Pfister S, Zhang W, Wang C, Wang P. Improving water ecosystem sustainability of urban water system by management strategies optimization. Journal of environmental management. 2020 Jan 15;254:109766.

26) Xu Z, Yao L, Zhou X, Moudi M, Zhang L. Optimal irrigation for sustainable development considering water rights transaction: A Stackelberg-Nash-Cournot equilibrium model. Journal of Hydrology. 2019 Aug 1;575:628-37. 
391

392

393
27) Yao L, Xu Z, Moudi M, Li Z. Optimal water allocation in Iran: a dynamic bi-level programming model. Water Supply. 2019 Jun 1;19(4):1120-8. 